\title{
A IMPORTÂNCIA DAS NOVAS MÍDIAS NA PROTEÇÃO DO MEIO AMBIENTE EM FACE DA CRISE AMBIENTAL
}

Denise Silva Nunes ${ }^{1}$

\section{Resumo}

Com o advento da globalização aliado às novas tecnologias, novos mecanismos de comunicação foram criados. Tem-se um novo espaço democrático, o qual serve de instrumento para expansão da informação, discussão e tomada de decisão. As novas mídias desempenham, no espaço virtual, novos atores de cidadania e participação. Assim, pretende-se neste trabalho discorrer sobre a importância das novas mídias na proteção do meio ambiente. Ainda, destacam-se os principais aspectos da crise ambiental decorrente do progresso tecnológico e a tutela ambiental no ordenamento jurídico brasileiro. Posteriormente, perspectivas e desafios às novas mídias na efetivação da proteção do meio ambiente. Palavras-chave: Crise ambiental. Novas mídias. Proteção.

\section{INTRODUÇÃO}

A sociedade passou por profundas transformações em que a realidade socioeconômica modificou-se com rapidez junto ao desenvolvimento incessante das economias de massas.

Os mecanismos de produção desenvolveram-se de tal forma a adequar às necessidades e vontades humanas. Contudo, o homem não mediu as possíveis consequências que tal desenvolvimento pudesse causar. Não apenas o meio natural foi alterado, como também a globalização e seus mecanismos trouxeram para grande parcela da população mundial o aumento da pobreza, desigualdade social, além dentre outros, a exclusão estrutural e cultural, como a perda de identidade cultural e social, dando lugar ao consumismo cultural. Ou seja, os avanços tecnológicos não tão adequados e preparados ameaçam aos Direitos Humanos, onde as classes excluídas sofrem diretamente muito mais com todo este cenário. Ainda, os padrões de consumo e a exigência por novas tecnologias causaram uma série de impactos ambientais caracterizando uma sociedade de risco ambiental, onde se faz necessária uma nova consciência ecológica em prol do desenvolvimento sustentável.

\footnotetext{
1 Bacharel em Direito pela Universidade Luterana do Brasil (ULBRA) Santa Maria, RS. E-mail: denise.silva.nunes@hotmail.com
} 
III SEMINÁRII ECDLOGIA

POLÍTICA

A preocupação com o meio ambiente é questionada, sendo centro de tomada de decisões, diante da grave problemática que ameaça romper com o equilíbrio ecológico do Planeta. Não apenas nos tradicionais meios de comunicação, como também nos espaços de interatividade, tem-se as novas mídias como novos meios de comunicação com função de instrumentos de proteção ambiental.

\section{Breves considerações acerca da crise ambiental}

A exploração irracional dos recursos naturais pelo homem desencadeou uma série de eventos negativos de proporções globais, onde a própria vida no Planeta se coloca em risco.

Tem-se na sociedade atual o risco ambiental, em que não se sabe exatamente quais as suas proporções e devidas consequências. E, de fato, o próprio homem se colocou na situação de crise ambiental e sociedade de risco, pois, adventos como a industrialização, a globalização, o crescimento populacional, as guerras mundiais, bem como a fixação da cultura do consumismo, aliada à falta de estrutura e adequação, contribuíram para o cenário. Para Raffaele de Giorgi (1998, p.193) o risco é a específica forma pela qual a sociedade representa e estabelece vínculos com o futuro.

No decorrer do tempo, constatou-se que o progresso cientifico no máximo proporcionou o progresso material ao homem, mas não necessariamente o progresso moral e ético, na mesma proporção (BOBBIO, 2000, p.663).

Sobre risco, Antony Giddens (2000, p.33) explica não ser o mesmo que infortúnio ou perigo. Risco se refere a infortúnios ativamente avaliados em relação a possibilidades futuras. A palavra só passa a ser amplamente utilizada em sociedades orientadas para o futuro - que veem o futuro precisamente como um território a ser conquistado ou colonizado. O conceito de risco pressupõe uma sociedade que atenta ativamente romper com o seu passado - de fato, a característica primordial da civilização industrial moderna.

Segundo Philippi Jr. (2003, p.50) o modelo de desenvolvimento econômico escolhido e assumido pelo governo brasileiro, nem sempre esteve associado ao meio ambiente, provocando, dentre outros, o incremento de uma sociedade dita consumista onde impera a força do mercado com regras que priorizam "ter" e não o "ser", a quantidade, não a qualidade, de vida ou de qualquer outro objeto, de onde emerge o 
vocábulo "descartável”, neologismo que provoca a geração alucinada de resíduos sólidos, de todos os tipos, tamanhos e matérias.

A crítica ao crescimento selvagem e a análise de seus custos sociais e ambientais estimularam uma extensa literatura e a formulação de importantes conceitos, como throughput e perverse growth (crescimento perverso), como também a reinterpretação do conceito marxista de faux frais (falsos custos) ou na concepção de George Bataille la part maudite (lado maldito), referente ao rendimento desperdiçado e riqueza estéril (SACHS, 2002, p.54).

Ainda, o modelo capitalista, irracional de exploração e apropriação dos recursos naturais, não apenas alterou o meio natural, mas também favoreceu o desencadeamento da miséria, da desigualdade social, da concentração de renda e a própria violação aos direitos fundamentais inerentes à pessoa humana.

Nesse sentido, as sociedades contemporâneas possuem um perfil de risco, o qual é potencializado em uma escala global. Sendo, inclusive, relacionado com os membros das futuras gerações através de resultados decisórios que são atribuídos a uma limitada participação, e restrita iniciativa de membros desta geração, responsáveis pela proliferação de riscos que são, portanto, além de globais, intergeracionais.

Ou seja, a responsabilidade pelos riscos globais possui problemas de democracia ambiental no que tange à participação decisória na gestão desses riscos, de modo que pode-se afirmar que os riscos ambientais também são consequências da falta de gestão adequada ou inexistente.

No entanto, verifica-se o crescimento da democracia ambiental, sendo visualizado na expansão da informação e discussão nos espaços virtuais, proporcionados pelo uso da internet. Tem-se, dessa forma, o nascimento de um novo instrumento de proteção do meio ambiente fomentado pelas novas mídias, o qual possui desafios para a sua plena efetivação.

\section{A tutela ambiental no Estado Democrático de Direito}

A Constituição Federal, conforme caput do artigo 225, dispõe sobre o direito ao meio ambiente ecologicamente equilibrado, bem de uso comum do povo e essencial à 
sadia qualidade de vida, impondo-se ao Poder Público e à coletividade o dever de defendê-lo e preservá-lo para as presentes e futuras gerações.

José Afonso da Silva (1997, p.2) aponta que o meio ambiente se constitui da "interação do conjunto de elementos naturais, artificiais e culturais que propiciem o desenvolvimento equilibrado da vida em todas as suas formas".

$\mathrm{O}$ direito ao meio ambiente ecologicamente equilibrado assumiu o status de direito fundamental, e foi consagrado um novo paradigma com relação à tutela ambiental, em prol do desenvolvimento sustentável.

No sentido jurídico, José Rubens Leite (2000, p.57) observa que a lei brasileira adotou um conceito amplo de meio ambiente, envolvendo a vida em todas as suas formas e, os seus elementos naturais, artificiais e culturais; identifica o meio ambiente ecologicamente equilibrado, como um macro bem unitário e integrado e, uma vez que considerando-o macro bem, tem-se que um bem incorpóreo e imaterial, com uma configuração também de micro bem. Trata-se de um bem de uso comum do povo, assumindo a característica de bem jurídico autônomo de interesse público. Conclui-se dizendo tratar-se, de fato, de um direito fundamental intergeracional, intercomunitário, incluindo a adoção de uma política de solidariedade.

Os princípios da prevenção e precaução são bases do sistema constitucional de proteção do meio ambiente, eis que eles informam o sistema jurídico de tutela do meio ambiente, em todos os seus aspectos - administrativo, cível, penal, nos termos do artigo $225, \S 3^{\circ}$, da nossa Constituição Federal.

Ainda, a Constituição Federal dispõe no seu artigo 225, VI a promoção da Educação Ambiental em todos os níveis de ensino e a conscientização pública. De acordo com o art. $3^{\circ}$ da mencionada Lei, incumbe ao Poder Público promover a educação ambiental em todos os níveis de ensino e o engajamento da sociedade na conservação, recuperação e melhoria do meio ambiente. E, aos meios de comunicação de massa, incumbem colaborar de maneira ativa e permanente na disseminação de informações e práticas educativas sobre o meio ambiente, e às empresas, entidades de classe, instituições públicas e privadas, promover programas destinados à capacitação dos trabalhadores, visando á melhoria e controle efetivo sobre o ambiente de trabalho, bem como sobre as repercussões do processo produtivo no meio ambiente. 

O sociólogo Pierre Lévy (1998), defende o potencial do ciberespaço com a possibilidade de uma nova forma de democracia através da apropriação das novas tecnologias. O "novo espaço do saber" seria a chave para profundas mudanças sociais, econômicas e políticas personificadas em um modelo de sociedade sem vínculos territoriais, relações institucionais ou laços de poder.

Sobre informação ambiental Flávia Tavares Lourdes (2004. p. 193) discorre que

O acesso à informação ambiental interliga direito e cidadania e prepara os caminhos que serão trilhados pela sociedade civil organizada e consciente de suas prerrogativas e obrigações. Isto porque a população carente de informação e instrução permite que o direito seja utilizado como instrumento de dominação, quando se deveria refletir sobre as relações e os conflitos estabelecidos no seio da sociedade, bem como as necessidades daqueles que são, ao mesmo tempo, criadores e destinatários do ordenamento jurídico.

Com a repercussão dos eventos ambientais nas redes de comunicação virtuais, verifica-se o crescimento da democracia ambiental, sendo visualizado na expansão da informação e discussão nos espaços virtuais, proporcionados pelo uso da internet.

Quanto ao direito à informação ambiental, remete ao cumprimento do dever jurídico de proteção e preservação para as atuais e futuras gerações. José Canotilho entende que o direito à informação abrange três níveis: o direito de informar, o direito de se informar e o direito de ser informado. Estes remetem à questão dos veículos de informação transmitir informações, bem como o indivíduo buscar se informar e à faculdade de ser mantido corretamente informado das questões ambientais.

Nesse sentido, as questões ambientais demandam respostas e os cidadãos com acesso à informação têm melhores condições de atuar sobre a sociedade, de articular mais eficazmente desejos e ideias e de tomar parte nas decisões que lhes dizem respeito diariamente.

Assim, a importância da informação ambiental consiste na contribuição para as análises e tomada de decisão sobre determinado risco ambiental. E a importância da efetivação do direito à informação é atrelada sobre os produtos e serviços consumidos, colaborando para a formação de uma sociedade de consumo consciente.

Para Pereira e Grau (2003, p.24l) os mecanismos de participação cidadã associados à formulação e/ou controle de políticas setoriais, como saúde, meio ambiente 
e educação, afloram em praticamente todos os países. Por outro lado, adquirem importância e respaldo jurídico as instituições de democracia direta (referendo, iniciativa popular, revogação de mandato), e se consagram ações de interesse público (direito de petição, amparo coletivo, ação de tutela, ação popular, etc.) associadas aos direitos de terceira geração relativos à defesa de direitos coletivos e difusos, bem como ao direito a um meio ambiente sadio e equilibrado, à competição, etc.

Conforme Édis Milaré (2005, p.222), as questões ambientais demandam respostas e "os cidadãos com acesso à informação têm melhores condições de atuar sobre a sociedade, de articular mais eficazmente desejos e ideias e de tomar parte nas decisões que lhes dizem respeito diariamente".

Tem-se, dessa forma, o nascimento de um novo instrumento de proteção do meio ambiente fomentado pelas novas mídias, o qual possui desafios para a sua plena efetivação.

\section{Perspectivas e desafios das novas mídias para a proteção ambiental}

Diante da sociedade de risco, a qual vivencia diversos impactos ambientais, inúmeros desafios estão à disposição da sociedade. Entende-se que as novas mídias possuem importância imensurável na expansão da informação ambiental, no espaço virtual interativo. Contudo, ações efetivas são necessárias para a proteção do meio ambiente. Verifica-se a tamanha importância das novas mídias, como novas relações construídas, a fim de adaptar à nova configuração que se estabelece entre ciência, sociedade e tecnologia.

Tendo em vista que os riscos não são riscos locais, mas sim, riscos de dimensões globais, faz-se necessário estabelecer vínculos e responsabilidades para assegurar um meio ambiente equilibrado às futuras gerações.

Entende-se que o meio ambiente e o crescimento econômico devem interagir de forma equilibrada, visto que ambos são fundamentais à existência humana. $\mathrm{O}$ meio ambiente e o desenvolvimento constituem-se direitos fundamentais que precisam ser efetivados e garantidos, sendo inseparáveis. Ressalta-se que cabe ao Poder Público e sociedade estabelecer critérios para o desenvolvimento, com ponderação de valores, corroborando, assim, para o crescimento econômico e preservação ambiental. 



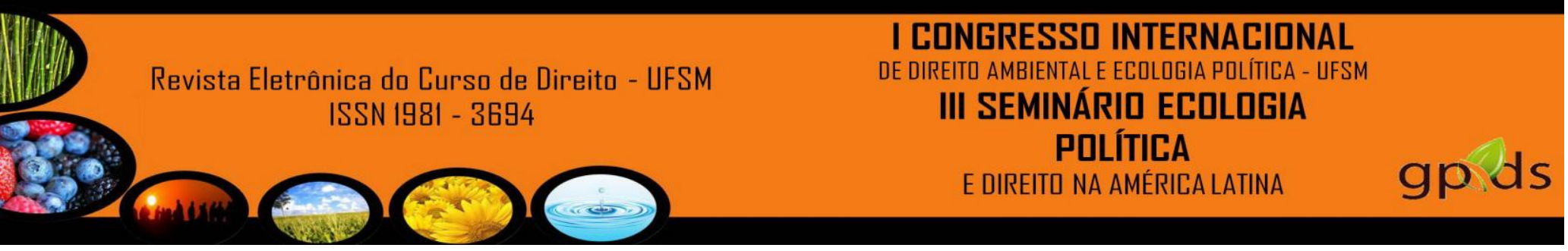

\section{REFERÊNCIAS BIBLIOGRÁFICAS}

BOBBIO, Norberto. Teoria Geral da Política. Rio de Janeiro. Editora Campus. 2000.

Constituição da República Federativa do Brasil, 31. ed. São Paulo: Saraiva, 2003.

GIDDENS, Antony. Mundo em descontrole: o que a globalização está fazendo de nós. Rio de Janeiro: Record, 2000.

GIORGI, Raffaele de. Direito, democracia e risco. Vínculos com o futuro. Porto Alegre: Safe, 1998.

HABERMAS, Jürgen. Consciência moral e agir comunicativo. Rio de Janeiro: Tempo Brasileiro, 1989.

LEITE. José Rubens Morato. Dano ambiental: do indivíduo ao coletivo extrapatrimonial. São Paulo: Revista dos Tribunais, 2000.

LOURES, Flávia Tavares Rocha. A implementação do direito à informação ambiental. In: Revista de Direito Ambiental. São Paulo: Revista dos Tribunais, $\mathrm{n}^{\mathbf{o}}$ 34, abril-junho, 2004.

MILARÉ, Édis. Direito do ambiente: doutrina, prática, jurisprudência, glossário. 4.ed. ver.atual. e ampl. São Paulo: RT, 2005.

PEREIRA E GRAU, PEREIRA, L.C.B.; GRAU, N.C. Entre o Estado e o Mercado: o Público não-estatal. Rio de Janeiro: FGV, 2003.

Philippi Jr. Urbanização e Meio Ambiente, Suetônio Mota, ABES, RJ, 2003.

SACHS, Ignacy. Caminhos para o desenvolvimento sustentável. 3 ed. 2002.

SILVA, José Afonso da. Direito Ambiental Constitucional. 2 ed. São Paulo: Maleiros, 1997 p. 2 .

SOUZA SANTOS, Boaventura. Pela mão de Alice. O social e o político na pósmodernidade. Porto: Afrontamento, 1994. 